\title{
(2iblioCanto?
}

\section{PRODUÇÃO ACADÊMICA SOBRE ARQUIVOS PRIVADOS: UMA ANÁLISE BIBLIOMÉTRICA NA BRAPCI}

PRIVATE ARCHIVES AND ACADEMIC PRODUCTION: A BIBLIOMETRIC ANALYSIS AT BRAPCI

\author{
Marcelo Calderari Miguel \\ marcelocalderari@yahoo.com.br \\ Rosa da Penha Ferreira da Costa (1) ${ }^{2}$ \\ rosapenha2020@gmail.com
}

Resumo: Trata-se de uma pesquisa bibliográfica que analisa a temática 'Arquivos Privados' nos periódicos da Ciência da Informação. Para identificar do material foi utilizada a Base de dados Referencial de Artigos de Periódicos em Ciência da Informação (BRAPCl). A análise enfoca três âmbitos: a) Levantar os artigos publicados sobre Arquivos Privados em periódicos da Ciência da Informação; b) Verificar quais os periódicos mais representativos para a área arquivística; c) Descrever o perfil dos autores mais produtivos de Arquivos Privados de acordo com sua titulação e instituição de origem. Observa-se como resultado 317 artigos, dos quais 207 se enquadraram nos parâmetros estabelecidos para realização deste estudo. Assim, a pesquisa revelou três revistas em atividade que mais publicaram a temática 'Arquivos Pessoais' são: Ágora: Arquivologia em Debate, com 41 artigos; Archeion Online com 14 artigos; Acervo: Revista do Arquivo Nacional com 11 artigos; e a revista descontinuada Arquivo \& Administração com 21 artigos.

\footnotetext{
1 Especialização em Matemática Financeira e Estatística - ALFAMÉRICA; Especialização em TECNOLOGIA EDUCACIONAL - IFES; Aperfeiçoamento em Educação Científica - UFMG; Graduação em Administração - UFES; Graduação em Biblioteconomia - UFES; Graduação em Ciências Contábeis - FEAD. Lattes: http://lattes.cnpq.br/5290994830537934

${ }^{2}$ Doutorado em Ciências da Informação - UnB. Mestrado em Artes - UFES. Especialização em Gestão Estratégica do Conhecimento e da Inovação - UFES. Especialização em Serviços de Informação Educativos - UFES. Graduação em Arquivologia - UFES. Graduação em Artes Plásticas UFES. Graduação em Biblioteconomia- UFES. Lattes: http://lattes.cnpq.br/3409664107216795
}

BiblioCanto, Natal, v. 5, n.1, p. 42 - 65, 2019. 


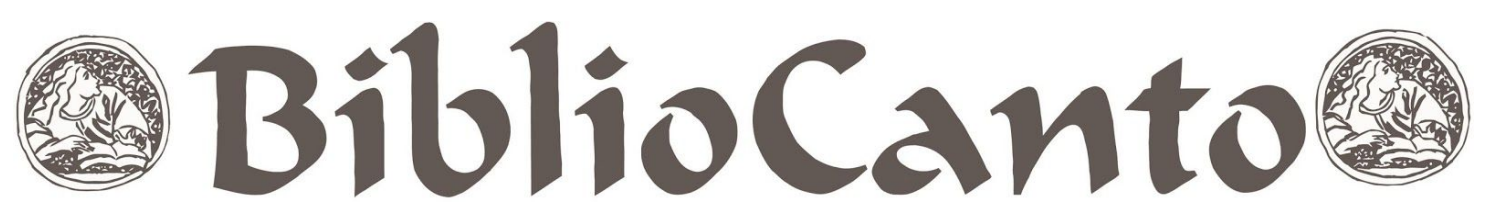

Palavras- chave: Arquivos Privados. Análise temática. Bibliometria. Produção científica. Periódicos Científicos.

\section{INTRODUÇÃO}

Os arquivos públicos e privados podem oferecer aos jovens e adultos a possibilidade de aprofundar estudos, resgatar memórias e enriquecer a vivência com conhecimentos encontrados em documentos nos mais diferentes suportes, independentemente de seu gênero, tais como fotografias. Com um ambiente da informação organizado, facilmente se encontram os assuntos procurados e os diversos interessados podem aprimorar seu aprendizado por meio dos arquivos, bem como também é possível a promoção da Cidadania Ativa, da cultura de paz e direitos humanos visando o desenvolvimento da democracia plural, participativa, criativa, empreendedora e sustentável.

A arquivística e a diplomática, com o passar do tempo, trazem um novo viés para o arquivista e os responsáveis por arquivos pessoais (privados, familiares, institucionais) são sujeitos capacitados para desenvolver projetos no processo de aprendizado desses lugares e dos múltiplos artefatos de informação. Entretanto, ainda existem paradigmas na arquivologia a serem modificados, principalmente nos quesitos Acesso X Acervo e isso é algo de permanente trabalho.

Muitas vezes, como uma tentativa de reparação histórica, a acolhida de 'arquivo privados' em órgãos públicos ocorre para proporcionar a valorização simbólica do fundo arquivístico. A "franquia de um arquivo privado ao público por qualquer meio, especialmente sua inclusão no acervo de uma instituição de preservação da memória, conduz a sua publicização - ação de tornar público, divulgar - e consequentemente a sua caracterização efetiva como arquivo" (VIANNA; LISSOVSKY; SÁ, 1986, p. 74).

Assim, encontrar Arquivos Privados preparados para 0 acesso dos pesquisadores, que ofereça estrutura planejada e desejada por seus detentores, ainda merece estudos e principalmente ações práticas. Diante das diversas funções de arquivo apresentadas pela Legislação Brasileira, entende-se que os 


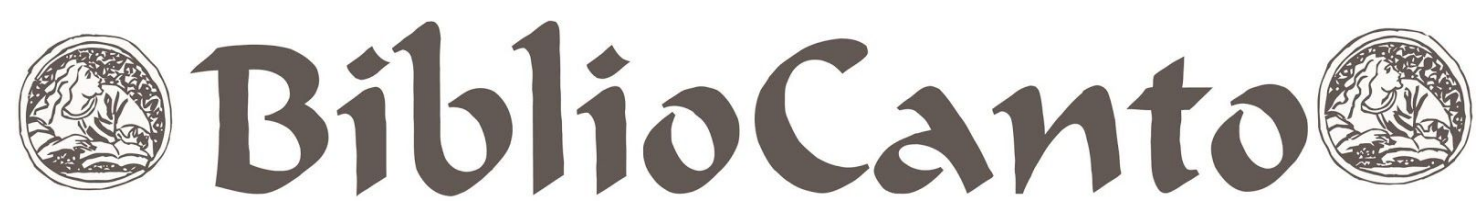

'Arquivos Privados' representam um forte potencial educativo, artístico e biográfico para o desenvolvimento de pesquisas e aprendizagem permanentes para redescoberta dos lugares de memória.

Em nova análise feita pelos historiadores, a partir da década de 1970, percebeu-se que, para fazer uma pesquisa histórica, as fontes não estão somente nos arquivos públicos, elas são encontradas também nos arquivos privados (MOLINA, 2013).

Ao observar o sítio eletrónico do Conselho Nacional de Desenvolvimento Científico e Tecnológico (CNPQ), nota-se a existência específica de três grupos de estudos direcionados a Arquivo Privado (foco pessoal, familiar, particular):

Grupo de pesquisa: Arquivos Pessoais, Patrimônio e Educação; Instituição: Universidade Federal do Rio Grande do Sul - UFRGS; Líderes: Doris Bittencourt Almeida \& Maria Teresa Santos Cunha, Área: Educação. Contato do grupo: almeida.doris@gmail.com.

Grupo de pesquisa: Núcleo de Pesquisas e Estudos em Arquivos Contemporâneos - NUPEAC; Instituição: UFSC; Líderes: Eliana Maria dos Santos Bahia Jacintho e Aline Carmes Krüger; Área: Ciência da Informação. Contato do grupo: eliana.maria@ufsc.br.

Grupo de pesquisa: Memória Social, Tecnologia e Informação; Instituição: Universidade Federal do Estado do Rio de Janeiro - UNIRIO; Líderes: Vera Lucia Doyle Louzada de Mattos Dodebei \& Leila Beatriz Ribeiro; Área: Ciência da Informação; Contato do grupo: dodebei@gmail.com.

Assim, o enfoque deste trabalho tem como base a pesquisa bibliográfica com o objetivo de analisar a esfera de aparição dos Arquivos Privados nos periódicos da Ciência da Informação. Com essa pesquisa pretende-se conhecer o histórico de alguns periódicos científicos que destacam a temática dos arquivos privados, mostrando assim desde quando e onde estão localizados e qual é o foco das revistas neste assunto. Convém destacar que tal assunto é amplo e há um rol de diferentes visões quanto a 'natureza e limites dos arquivos', conforme apontam os estudos de Calderon (2013) e Vitoriano (2016). 


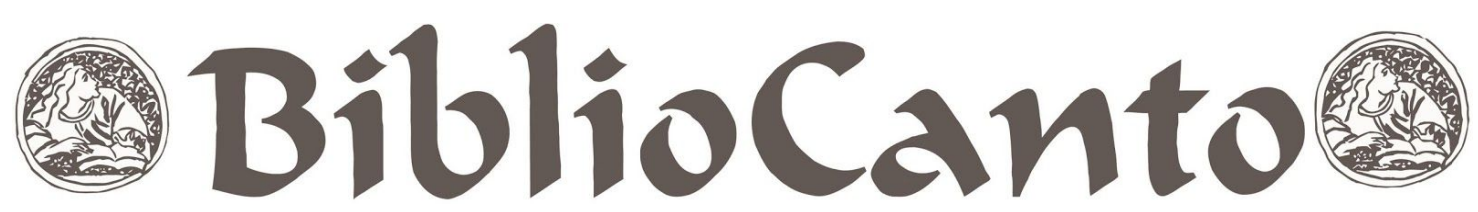

Diante dos desafios e provocações que esta temática expressa no âmbito da comunicação e ciência da informação, traçam-se três objetivos específicos: a) Levantar os artigos publicados com foco em 'Arquivos Privados' em periódicos da Ciência da Informação; b) Identificar quais revistas têm maior representatividade nos âmbitos de promoção de estudos sobre Arquivos Privados; c) Descrever o perfil dos autores mais produtivos na área arquivística de acordo com sua titulação e instituição de origem. Por conseguinte, o estudo identifica artigos nos periódicos da Ciência da Informação que tenham por escopo estruturar uma abordagem envolvendo a temática 'Arquivos Privados' no âmbito das produções acadêmicas.

\section{REFLEXÕES TEÓRICAS E PRÁTICAS}

O Estado francês no século XIX já incluía no campo da legislação, diretrizes sobre arquivos aos fundos de natureza privada de origem familiar. Portanto, registra-se uma das primeiras incorporação do conceito de arquivo privado pela arquivística no contexto do século XX (FRAIZ, 1998). Dessa forma, acrescenta a autora, foi somente a partir da segunda metade deste século que o arranjo de papéis privados deixou de se basear somente em práticas e métodos biblioteconômicos, ou seja, desenvolve-se uma preocupação no que tange os arquivos privados sobre os princípios de proveniência e do respeito à ordem original adotados no arranjo de arquivos públicos.

A historiadora francesa Anne Zink declara que itens mais significativos num arquivo, seu conjunto 'mais precioso', são os documentos que não têm nenhum equivalente institucional, ou seja, que não têm cópias em lugar algum (CAMARGO, 2009). Zink aponta que:

[...] os itens mais significativos num arquivo pessoal são os diários íntimos, os livros de despesas domésticas e, sobretudo, a correspondência, na qual é possível encontrar modos de sentir e motivações. O conjunto equivale, pelo menos parcialmente, aos chamados egodocumentos ou àqueles que, sob o ambíguo rótulo de arquivos autobiográficos, têm alimentado hoje um vasto campo de pesquisa (apud CAMARGO, 2009, p. 30).

Ainda convém lembrar, como propõem (MOURA; GARCIA, 1998, p. 175), que embora a formação de arquivos de pessoas singulares e de famílias remonte 


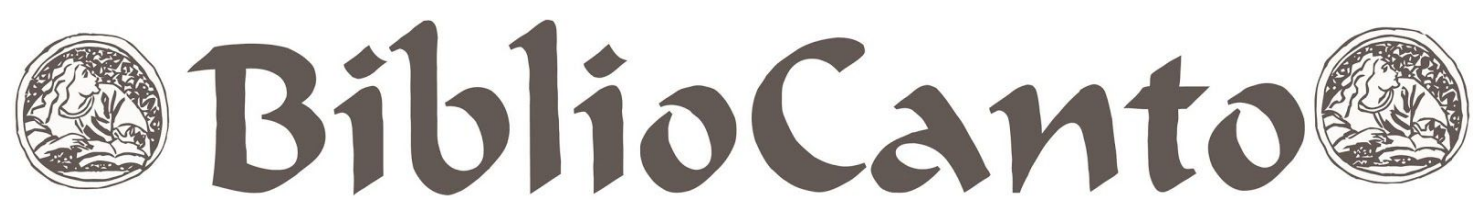

“a épocas muito recuadas, a noção de 'arquivo privado' demorou a ser acolhida pela doutrina e pela legislação, porque os conjuntos documentais de entes privados não eram qualificados como 'arquivos' [...] esta concepção prevaleceu durante muitos séculos".

Assim, até ao princípio deste século, o Estado interessou-se primordialmente pela recuperação dos 'actos públicos' que integravam os arquivos privados. Também nos arquivos privados contemporâneos de personalidades que desenvolveram atividades de relevância na administração pública e na vida política e cultural se encontram documentos pertença do Estado, subtraídos da sua sede natural, para se inc1uirem nesses papéis pessoais (MOURA; GARCIA, 1998, p. 178).

A formação de um arquivo privado se concretiza na medida em que o titular passa a agrupar documentos resultantes de conjuntos de atos, em concordância com o seu modo de vida. Assim, Lopez (2003) argumenta que nos arquivos privado é necessário identificar as inter-relações entre as atividades do titular e os documentos por ele acumulados/produzidos, pois somente a árdua recomposição da conjuntura de produção documental é capaz de dotar tais acervos de significado arquivístico.

A propósito de averiguar como o tema arquivo privado (familiar, empresarial, particular, pessoal ou egodocumental) vem sendo utilizada por uma série de investigadores motivados pelas discussões em torno das tradições e dos processos de construção/recuperação de memórias e dos processos de criação (do artista, cientistas, ideólogos), tem surgido vários estudos e estão sendo desenvolvidas inúmeras pesquisas. Um exemplo de avanços nessa perspectiva situa-se o acervo do Centro de Pesquisa e Documentação de História Contemporânea do Brasil (CPDOC) que vale-se do Programa de Arquivos Pessoais (PAP) e entende-se que:

Os arquivos pessoais constituem valiosas fontes de pesquisa, seja pela especificidade dos tipos documentais que os caracterizam, seja pela possibilidade que oferecem de complementar informações constantes em arquivos de natureza pública [...] Em virtude de conterem informações fundamentais para a recuperação da memória ou para o desenvolvimento da pesquisa [...] O Brasil hoje já dispõe de um corpo de leis regulamentando várias questões na área de arquivos, entre elas, o acesso a informações de natureza privada. Além da lei 8.159, de 1991, conhecida como Lei de Arquivos, que possui um capítulo dedicado aos arquivos privados, o decreto 2.942, de 1999, e a Resolução $n^{\circ} 12$, do Conselho Nacional de Arquivos CONARQ, estão voltados para o tema (FUNDAÇÃO GETULIO VARGAS, 2017, p. 1). 


\section{(2) BiblioCanto?}

Oliveira (2012, p. 33) esclarece que os arquivos econômicos, sociais e pessoais expressam alguns exemplos de arquivos privados que, "de forma genérica, dizem respeito a um conjunto de documentos produzidos ou recebidos por pessoas físicas ou jurídicas em virtude de suas atividades". Nas questões de 'patrimonialização do patrimônio', ou seja, a institucionalização de mecanismos de proteção do patrimônio cultural, material e documental, a utilização dos Arquivos Privados têm importante papel de resguardar um bem e reconstituir saberes.

Chaves (2017, p. 24), considerando o sentido mais pleno dos arquivos empresariais, aponta que tais constituem "um manancial" de informações que carecem ser preservadas e apreciadas porque "[...] oferecerem um leque maior $\mathrm{e}$ mais diversificado para as pesquisas científicas. As próprias plantas e seu entorno são objetos fascinantes de pesquisas arqueológicas a revelarem costumes e padrões técnicos de uma época". Assim, a seguir apresentam-se algumas perspectivas de análise com essa temática.

\section{PERCURSO METODOLÓGICO}

A metodologia deste trabalho caracteriza-se como uma pesquisa bibliográfica; o estudo utiliza uma abordagem quantitativa e qualitativa tanto para coletar os dados, como para o tratamento destes; dessa forma desenha-se um cunho exploratório no sentido de obter familiaridade com o problema.

Já no que tange os objetivos apresenta-se uma composição descritiva que busca por meio de uma pesquisa bibliográfica levantar a temática, além de selecionar leituras, documentos e discussão sobre a mesma. Acerca de Arquivo Privado compreende que são: 1) Arquivo de entidade coletiva de direito privado, família ou pessoa - também chamado arquivo particular e; 2) Arquivo de uma família ou de seus membros, relativo às suas atividades públicas e privadas, inclusive à administração de seus bens - também chamado arquivo familial ou arquivo familiar (DIBRATE, 2005).

No que tange a delimitação do estudo, a busca da base de dados que 


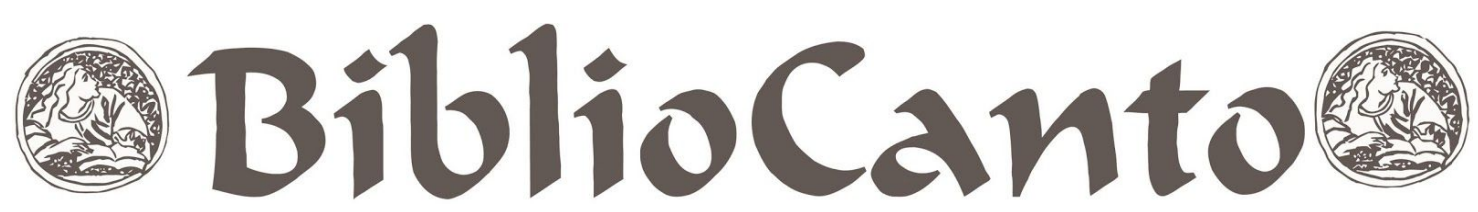

convém a especificidade da análise é demarcada pelo âmbito da Base de Dados Referencial de Artigos de Periódicos em Ciência da Informação (Brapci), cuja função é reunir as revistas científicas da área da Ciência da Informação, permitindo realizar a formulação de busca ampla nos periódicos indexados sobre a temática, bem como, sistematizar as buscas referenciais.

Acerca da Base de Dados Referenciais de Artigos de Periódicos em Ciência da Informação (Brapci), Bufrem et al. (2010, p. 25) destaca as seguintes particularidades: a) indexa os periódicos e anais de congressos científicos da área de Ciência da Informação; b) a revista mais antiga desta base data o ano de 1972; c) a base de dados facilita o acesso e a consulta direta a 57 revistas científicas da Ciência da Informação, indicando diversos pesquisas publicadas em Revistas Científicas, Trabalhos em Eventos, Livros, Tese de autores da área.

\begin{abstract}
A Base de Dados Referenciais de Artigos de Periódicos em Ciência da Informação (Brapci) é o produto de informação do projeto de pesquisa 'Opções metodológicas em pesquisa: a contribuição da área da informação para a produção de saberes no ensino superior', cujo objetivo é subsidiar estudos e propostas na área de Ciência da Informação, fundamentando-se em atividades planejadas institucionalmente. [...] A Brapci amplia o espaço documentário permitido ao pesquisador, facilita a visão de conjunto da produção na área, ao mesmo tempo, que revela especificidades do domínio científico [...] (BUFREM et al., 2010, p. 25).
\end{abstract}

O estudo foi realizado no início do segundo semestre de 2019 (10 jul.), com a observação direta e organização dos resultados da busca (arquivo: familiar, empresarial, particular, privado e pessoal) organizando a contagem e exclusão das repetições de documentos. Os dados foram coletados e tabulados no software $M$. Excel sendo que houve um tratamento para agrupamento, filtro e descrição desses registros de acordo com a expressividade numérica dos registros recuperados em revistas científicas. Assim, a análise dos dados ocorre com base no princípio da bibliometria que é uma análise da atividade científica ou técnica pelos estudos quantitativos das publicações (SILVA; HAYASHI; HAYASHI, 2011).

Cabe destacar que a análise bibliométrica se "expandiu em várias áreas, especialmente na Ciência da Informação e consolida-se fortemente a partir de 1979, com a publicação do periódico internacional Scientometrics" (VANZ; SANTIN; 


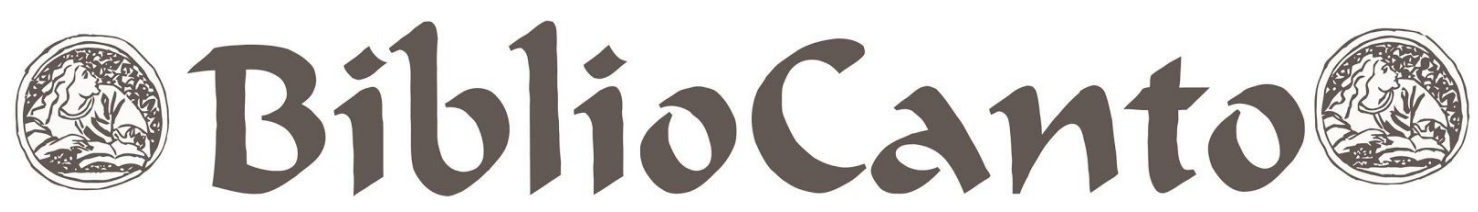

PAVÃo, 2018, p. 8). Destarte, o "uso da bibliometria para a avaliação sistemática da pesquisa, com o objetivo de fundamentar as decisões estratégicas sobre políticas em C\&T, já é comum em vários países, nos quais a bibliometria vem se tornando uma prática institucionalizada" (VANZ; SANTIN; PAVÃO, 2018, p. 10).

Contudo, para Silva, Hayashi e Hayashi (2011, p. 126) a presença dos profissionais da área de Ciência da Informação na realização de análises bibliométricas ainda é tímida, quando comparada com a de especialistas de outras áreas de conhecimento. Entretanto, convém destacar que a bibliometria vem se consolidando como instrumento de gestão da pesquisa e uma ferramenta a "mais para subsidiar a tomada de decisões acerca das políticas científicas: é um instrumento útil para identificar os agentes mais capazes em uma comunidade e orientar a correta alocação de recursos e o estabelecimento de prioridades" (VANZ; SANTIN; PAVÃO, 2018, p. 8).

Desta forma, considera-se que indicadores bibliométricos contribuem amplamente para entender e pautar novos estudos acerca dos 'arquivos privados' na ciência, tecnologia e recriação (artística, histórica, cinematográfica, antropológica). Portanto, essa pesquisa pauta uma análise bibliométrica de uma parte da produção científica sobre 'arquivos privados', por artigos representados na base de dados Brapci. A seguir apresentam-se os resultados e a respectiva análise com essa temática.

\section{APRESENTAÇÃO, ANÁLISE E DISCUSSÃO DOS RESULTADOS}

A análise surge por meio do levantamento com o termo 'Arquivo' na Brapci, o qual pesquisado utilizando-se cinco composições, assim definidas: arquivo famili* (27 itens documentais recuperados); arquivo empresari* (26 itens); arquivo particul* (49 indicações); arquivo priva* (80 itens); e arquivo pesso* (135 indicações). O total remete a 317 itens documentais recuperados; na análise se exclui as dez repetições de registros e isso resulta em um conjunto com 307 indicações documentais - $2^{\mathrm{a}}$ etapa de filtragem, como pode ser observado na Figura 1, ilustração em forma de diagrama de Venn em modelo de Grünbaum. 


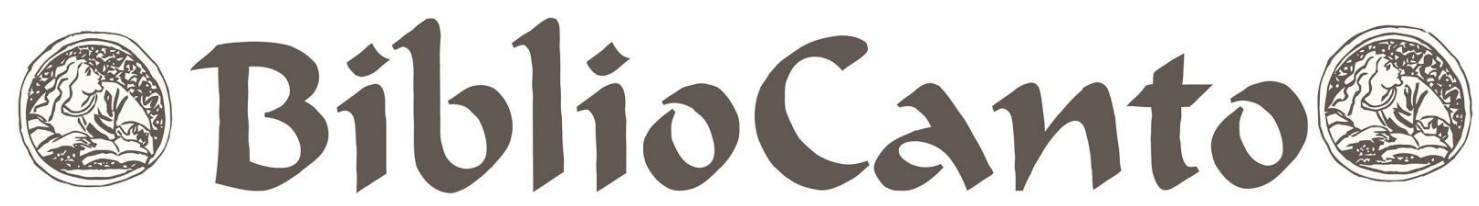

Figura 1- Produção documental sobre 'arquivos privados' (1975-2019) na Brapci

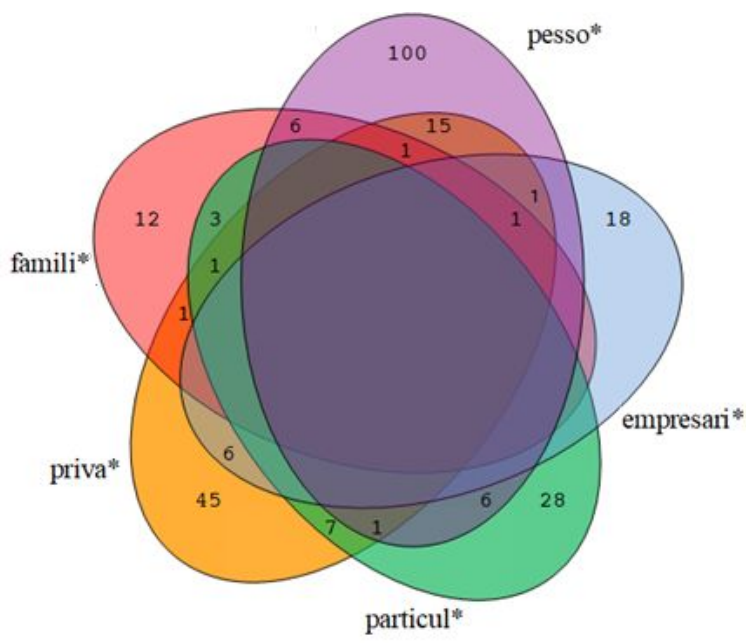

Fonte: Elaboração própria (2019).

Convém destacar que a $2^{a}$ etapa apresenta itens documentais diversos como: artigos, relatos de pesquisas, editoriais, notas, Trabalho de conclusão de curso (TCC), Pôsteres e Anais dos Encontros Nacionais de Pesquisa em Pós-Graduação em Ciência da Informação (ENANCIB). Assim, com a próxima etapa de triagem acentua-se a seleção documental, estratégia como informe do(s) termo(s) de busca por todos os campos (palavras-chave, referências, resumo, título) e refinado com uso de asterisco, permanecendo, portanto, o rol apreciativo a artigos científicos e relatos de pesquisa, o que resulta em 207 itens sobre a temática pesquisada (10 de julho de 2019) na Brapci.

Tabela 1 - Seleção, explanação e análise: filtragem diagnóstica

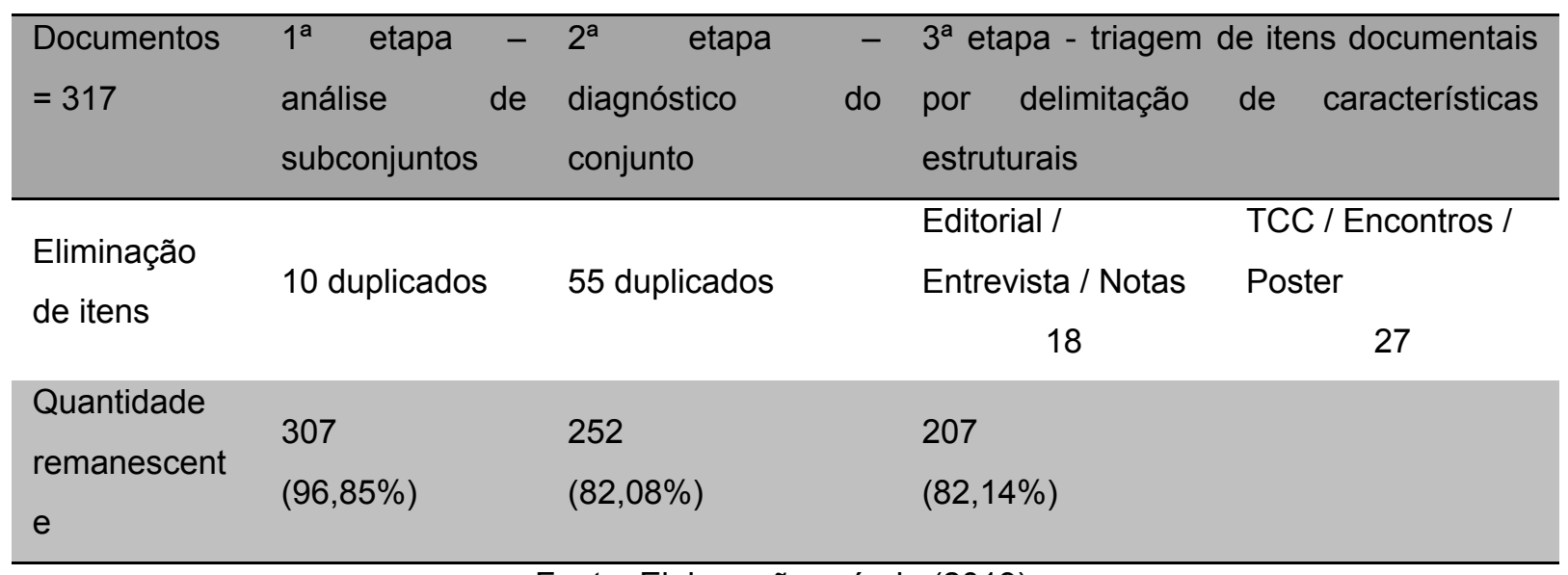

Fonte: Elaboração própria (2019).

Segundo a tabela 1 , os itens documentais atinentes a temática em estudo 


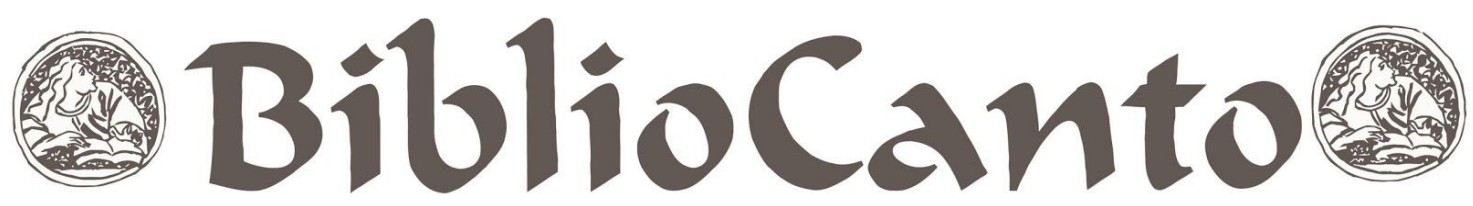

são dimensionalizados em que cada nível de seleção destrinchado pelas determinantes aplicáveis a eles. Assim, com a análise direta dos registros da base de dados, pode-se apreender que desde 2005 (Figura 2) há difusão de pesquisas e estudos acadêmico-científicos com título, palavras-chave ou resumo abarcando 'arquivos privados'. O anseio por essa temática é estendido dado o enfoque da Lei de Acesso a Informação e a ampliação dos Programas de Pós-Graduação em Ciência da Informação (PPGCI) no país.

De tal modo, os 207 itens documentais (de 1975 a jun. de 2019) reavidos na Brapci compõem corpus literário paralelo para a discussão acerca dos 'arquivos privados' (e das terminologias similares); deste modo a pesquisa não adentra em itens recuperados de editoriais e conferências, todavia foca artigos e relatos de experiências.

Figura 2 - Recorte da produção acadêmico-científica sobre arquivos privados (2005-2019) com base nos dados da Brapci

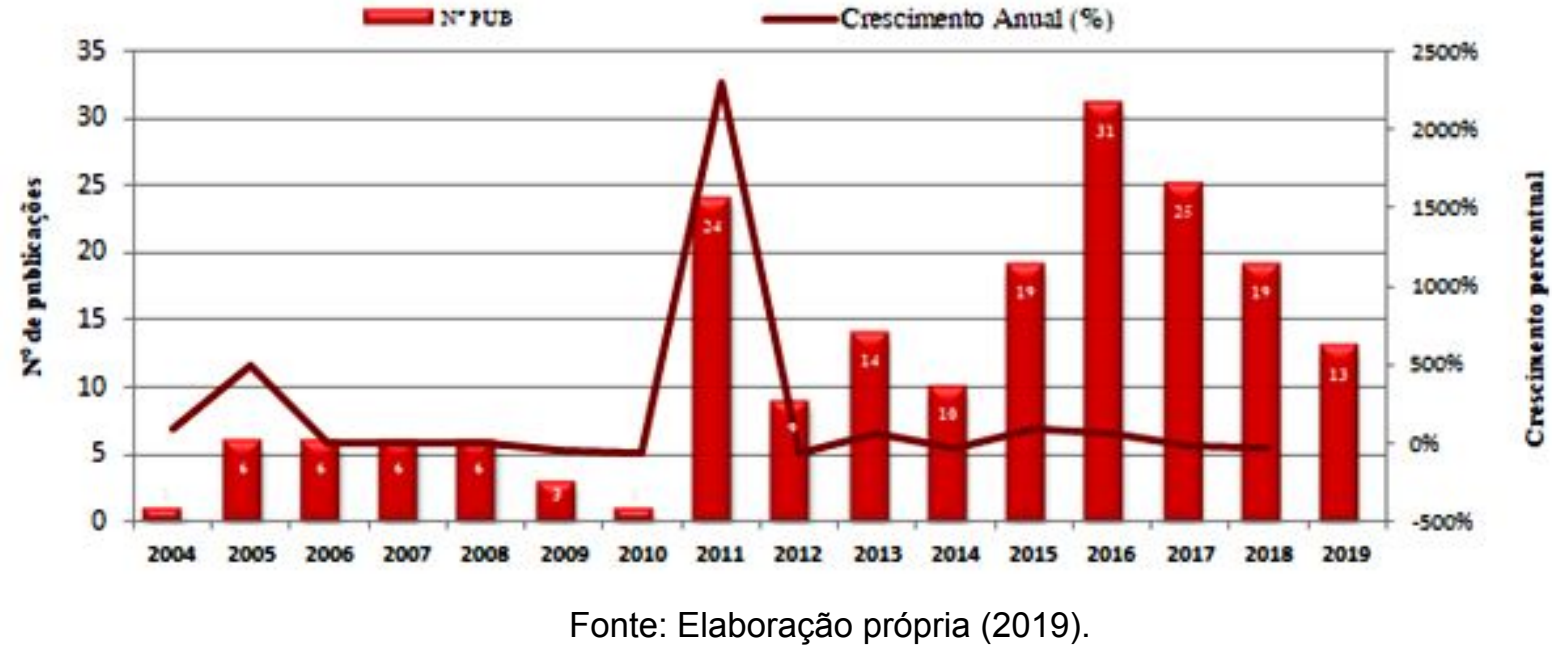

Importante frisar também, que, a análise se detém ao grupo de $207(82,14 \%)$ localizado na Brapci - busca sem aspas, refinado com carater-curinga (Figura 1) e termo(s) de busca envolvendo os campos 'todos'. Assim se recupera itens que apresentam pontos de especificidade a temática acolhida; após seleção apura-se 39 periódicos (Tabela 2).

Tabela 2 - Periódicos da Cl direcionado a 'Arquivos Privados'

\begin{tabular}{l|l|c|c|c}
\hline Periódicos Científicos & ISSN & Qualis & Artigos & Totais \\
\hline Perspectivas Em Ciência Da Informação & $1981-5344$ & A1 & 5 & \multirow{2}{*}{ (4) } \\
Transinformação & $2318-0889$ & A1 & 3 & $(4,83 \%)$
\end{tabular}

BiblioCanto, Natal, v. 5, n.1, p. $42-65,2019$. 


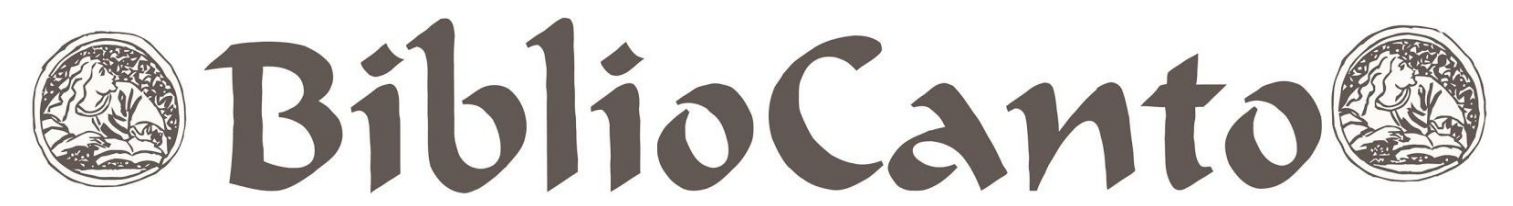

\begin{tabular}{|c|c|c|c|c|}
\hline Informação \& Sociedade: Estudos & 0104-0146 & A1 & 2 & \\
\hline Informação \& Informação & $1414-2139$ & $\mathrm{~A} 2$ & 6 & \multirow{4}{*}{$\begin{array}{l}14 \\
(6,76 \%)\end{array}$} \\
\hline Encontros Bibli (Ufsc) & $1518-2924$ & A2 & 4 & \\
\hline Em Questão (Ufrgs) & $1807-8893$ & $\mathrm{~A} 2$ & 3 & \\
\hline Revista Interamericana de Bibliotecología & $0120-0976$ & A2 & 1 & \\
\hline Ágora: Arquivologia em Debate & 0103-3557 & B1 & 41 & \multirow{12}{*}{$\begin{array}{l}94 \\
(45,41 \% \\
)^{4}\end{array}$} \\
\hline Arquivo \& Administração & $0100-2244$ & B1 & 21 & \\
\hline $\begin{array}{l}\text { RBBD. Revista Brasileira de Biblioteconomia } \\
\text { e Documentação (Online) }\end{array}$ & $1980-6949$ & B1 & 7 & \\
\hline Pontodeacesso (Ufba) & $1981-6766$ & B1 & 6 & \\
\hline Ciência da Informação (Online) & $1518-8353$ & B1 & 3 & \\
\hline $\begin{array}{l}\text { Incid: Revista de Documentação e Ciência } \\
\text { da Informação }\end{array}$ & $2178-2075$ & B1 & 3 & \\
\hline $\begin{array}{l}\text { Rici: Revista Ibero-Americana de Ciência da } \\
\text { Informação }\end{array}$ & $1983-5213$ & B1 & 3 & \\
\hline $\begin{array}{l}\text { Pesquisa Brasileira em Ciência da } \\
\text { Informação e Biblioteconomia }\end{array}$ & $1981-0695$ & B1 & 3 & \\
\hline Liinc Em Revista & $1808-3536$ & B1 & 2 & \\
\hline Bjis: Brazilian Journal Of Information Science & $1981-1640$ & B1 & 2 & \\
\hline $\begin{array}{l}\text { Rdbci: Revista Digital de Biblioteconomia e } \\
\text { Ciência da Informação }\end{array}$ & 1678-765X & B1 & 2 & \\
\hline Perspectivas em Gestão \& Conhecimento & $2236-417 X$ & B1 & 1 & \\
\hline Acervo: Revista Do Arquivo Nacional & $2237-8723$ & B2 & 11 & \multirow{4}{*}{$\begin{array}{l}25 \\
(12,08 \% \\
)\end{array}$} \\
\hline $\begin{array}{l}\text { Revista ACB: Biblioteconomia em Santa } \\
\text { Catarina }\end{array}$ & $1414-0594$ & B2 & 8 & \\
\hline $\begin{array}{l}\text { Cadernos Bad - Biblioteconomia, Arquivística } \\
\text { e Documentação (Portugual) }\end{array}$ & $0007-9421$ & B2 & 5 & \\
\hline $\begin{array}{l}\text { Atoz: Novas Práticas em Informação e } \\
\text { Conhecimento }\end{array}$ & $2237-826 X$ & B2 & 1 & \\
\hline Biblos (Rio Grande) & $0102-4388$ & B3 & 2 & $\begin{array}{l}2 \\
(0,97 \%)\end{array}$ \\
\hline Páginas A\&B Arquivos e Bibliotecas & 0873-5670 & B4 & 7 & $\begin{array}{l}7 \\
(3,38 \%)\end{array}$ \\
\hline Biblionline (João Pessoa) & $1809-4775$ & B5 & 9 & \multirow{9}{*}{$\begin{array}{l}31 \\
(14,98 \% \\
)\end{array}$} \\
\hline Informação Arquivistica & $2316-7300$ & B5 & 8 & \\
\hline Múltiplos Olhares em Ciência da Informação & $2237-6658$ & B5 & 4 & \\
\hline $\begin{array}{l}\text { Revista Analisando em Ciência da } \\
\text { Informação }\end{array}$ & $2317-9708$ & B5 & 3 & \\
\hline Prisma.Com (Portugual) & $1646-3153$ & B5 & 2 & \\
\hline Ciência da Informação em Revista & $2358-0763$ & B5 & 2 & \\
\hline Logeion: Filosofia da Informação & $2358-7806$ & B5 & 1 & \\
\hline Informação em Pauta & $2525-3468$ & B5 & 1 & \\
\hline Revista Conhecimento em Ação & $2525-7935$ & B5 & 1 & \\
\hline Archeion Online & $2318-6186$ & C & 14 & $\begin{array}{l}14 \\
(6,76 \%)\end{array}$ \\
\hline Arquivística. Net & $1808-4826$ & * & 6 & \multirow{3}{*}{$\begin{array}{l}10 \\
(4,83 \%)\end{array}$} \\
\hline Revista de Biblioteconomia de Brasília & 0100-7157 & * & 2 & \\
\hline $\begin{array}{l}\text { Risc: Revista Informação na Sociedade } \\
\text { Contemporânea }\end{array}$ & 2447-0198 & * & 1 & \\
\hline
\end{tabular}




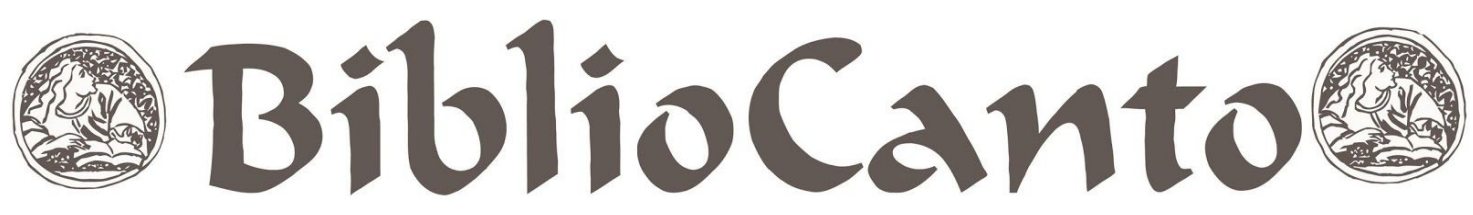

Conci: Convergência em Ciência da $2595-4768$ 1

Informação

Fonte: Dados recuperados na BRAPCI (2019), organização conforme Avaliação Capes Qualis (2013-2016). *Periódicos não avaliados

A tabela 2 reporta as revistas e a quantidade de publicações encontradas na âmbito da Brapci e do tema de investigação, conforme a Área de Avaliação Capes Comunicação e Informação - Qualis quadriênio 2013-2016. A ilustração a seguir (Figura 3) sinaliza os títulos de periódicos e quantidade de respectivos itens documentais que retorna na busca da base de dados.

Figura 3 - Representação da temática 'arquivos privados' em número de publicações científicas

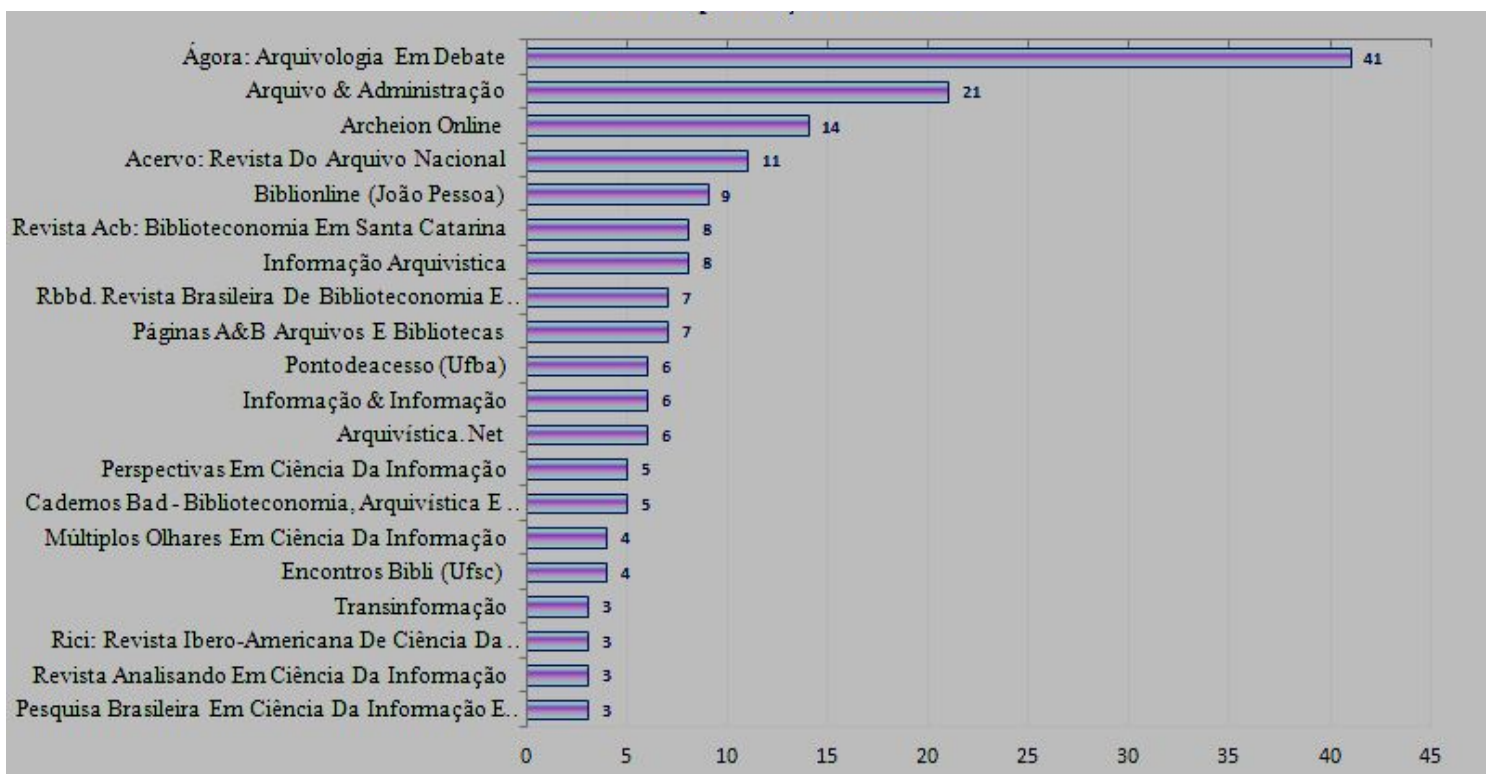

Fonte: Autores, com base em dados recuperados na Brapci no período de 1975 a jun. de 2019.

Através do estudo focal, demonstram-se a análise a seguir os quatro títulos de periódicos ativos indexados na Brapci, que subsidiam e favorecem o desenvolvimento da produção científica envolvendo a 'ambientude' dos arquivos privados. Após isso, traz-se à tona a discussão e reflexão a respeito da praxia de pesquisadores (e respectivas instituições) e do periódico (inativo) 'Arquivo \& Administração' na propagação do tema em análise.

\section{1 Ágora (Florianópolis): Arquivologia Em Debate}

A revista Ágora foi criada no ano de 1985 e nasce com a marca de ser a 


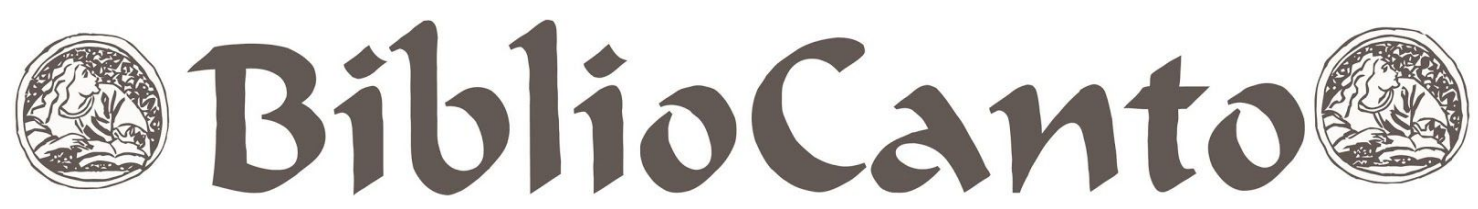

primeira publicação científica e específica de Arquivologia no país e na América Latina. O periódico é atualmente editado pela equipe do Departamento de Ciência da Informação da Universidade Federal de Santa Catarina (UFSC) e tem periodicidade semestral.

A Ágora surgiu de uma parceria entre o Arquivo Público do Estado de Santa Catarina e o Curso de Arquivologia da UFSC, foca a Área de Estudo da Ciência da informação. A diretriz do periódico expressa que a "ÁGORA - entre os antigos gregos, a sua praça pública, o local de assembleias - será um veículo de divulgação e debate sobre os problemas pertinentes ao Arquivo Público e, por extensão, da Memória Catarinense" (PIAZZA, 1985, p. 1). Com esse enfoque, a primeira edição, lançada no segundo semestre de 1985 teve apoio de três instituições: o Arquivo Público do Estado de Santa Catarina, a Universidade Federal de Santa Catarina e a Associação de Amigos do Arquivo Público do Estado de Santa Catarina - AAAPSC (entidade que encerrou as atividades em 2015).

A revista recebeu, na avaliação do quadriênio 2013/2016 os estratos Qualis nas áreas: Comunicação e Informação B1. Analisando os arquivos recuperados na Base de Dados em Ciência da Informação (Brapci) localiza-se 41 publicações (Tabela 3) com os parâmetros estabelecidos na busca por Arquivos Privados:

Tabela 3 - Artigos de Periódicos relacionado conforme busca na Brapci

\begin{tabular}{l|c|c|c|c|c|c|c|c|c|c}
\hline Ano & 2002 & 2011 & 2012 & 2013 & 2014 & 2015 & 2016 & 2017 & 2018 & 2019 \\
\hline \multirow{2}{*}{ Quantidade } & 1 & 17 & 3 & 2 & 1 & 4 & 2 & 2 & 2 & 7 \\
de artigos & 2,44 & 41,46 & 7,32 & 4,88 & 2,44 & 9,76 & 4,88 & 4,88 & 4,88 & 17,07 \\
& $\%$ & $\%$ & $\%$ & $\%$ & $\%$ & $\%$ & $\%$ & $\%$ & $\%$ & $\%$ \\
Quantidade & 1 & 14 & 4 & 3 & 1 & 6 & 5 & 5 & 8 & 13 \\
de autores & & & & & & & & & & \\
\hline
\end{tabular}

Fonte: Autores, com base na Brapci, (jun. 2019).

Cabe observar os trabalhos com o tema segue crescente na Revista Ágora o número de publicações sobre o tema tem aumentado e especialmente destacam-se publicações com mais de uma autoria (Tabela 3), sendo que há um total de 41 artigos e 59 autores. Assim, com uma busca por "Arquivo particular" diretamente na webpagina da Ágora (campo 'conteúdo da revista' da UFSC, ISSN 0103-3557) localiza-se o quantitativo de 440 itens documentais. Deste modo, 


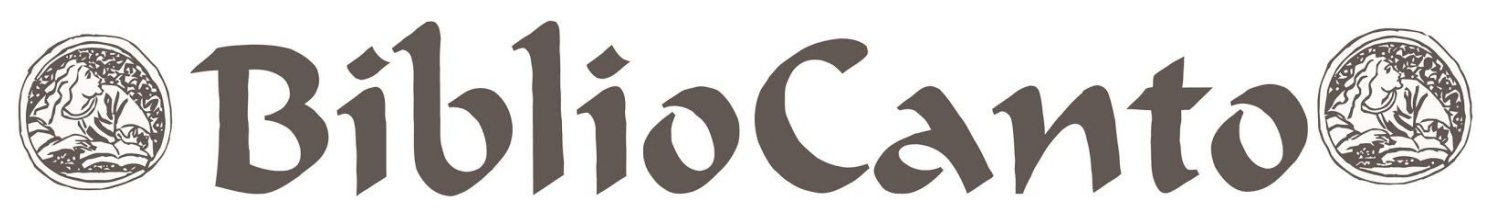

averigua-se que a Ágora foca a Área de Estudo da $\mathrm{Cl}$ - e assim foi além dos redutos público e dos horizontes Catarinenses - a revista dá visibilidade a comunicações sobre Administração de Arquivos, Arquivos digitais, Tecnologia da informação aplicada aos arquivos, $\mathrm{Cl}$, Documentação, Diplomática, História e Sociologia aplicada aos arquivos.

\subsection{Arquivo \& Administração}

Cabe destacar que a Brapci localiza uma vasta gama de produção acadêmica sobre arquivos privados no contexto da revista Arquivo \& Administração. Esse foi um periódico relevante que surgiu da associação dos Arquivistas Brasileiros (AAB), fundada em 1971 e a que buscava de forma técnica, científica, cultural e profissional contribuir para o desenvolvimento e aperfeiçoamento dos profissionais de arquivo e da Arquivologia; propunha a cooperação entre entidades públicas e privadas, nacionais e internacionais em tudo que fosse relevante a difusão do trabalho e do saber arquivístico.

A base de dados da Biblioteca Maria Beatriz Nascimento, do Arquivo Nacional disponibiliza, tornou disponível online toda a coleção da Revista Arquivo \& Administração para download. O primeiro número foi lançado em 1972, tendo periodicidade semestral, disponibilizada no sítio eletrônico da AAB. Assim com tal ciclo de vida recupera-se na Brapci 15 indicações documentais sobre a temática específica a Arquivos Privados - que em 1978 pautou a abordagem sobre a especificidade 'privada' dos arquivos e ao fechar a última edição em 2014, com os 42 anos, averigua-se que publicações centrais e transversais no mesmo víeis, sendo que há 34 autores no total de 21 artigos, sendo 12 no período 2005-2014. Os artigos publicados na Revista Arquivo \& Administração com a temática focal em arquivos privados são:

Tabela 4 - Artigos de Periódicos relacionado ao tema arquivos privados

\begin{tabular}{|c|c|c|c|c|c|c|c|c|c|c|c|c|}
\hline Ano & & 1975 & 1978 & 1979 & 1986 & 1998 & 2008 & 2010 & 2011 & 2012 & 2013 & 2014 \\
\hline & $n$ & 2 & 2 & 1 & 3 & 1 & 3 & 1 & 1 & 4 & 2 & 1 \\
\hline & $\%$ & 9,50 & 9,50 & 4,80 & $\begin{array}{l}14,3 \\
0\end{array}$ & 4,80 & $\begin{array}{l}14,3 \\
0\end{array}$ & 4,80 & 4,80 & $\begin{array}{l}19,0 \\
0\end{array}$ & 9,50 & 4,80 \\
\hline
\end{tabular}




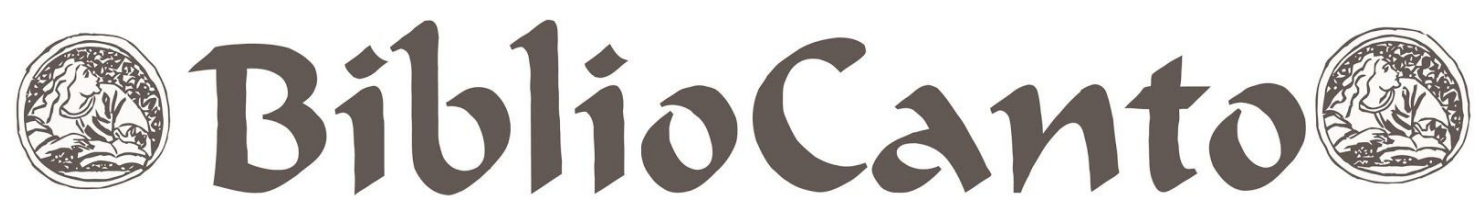

Quantidade

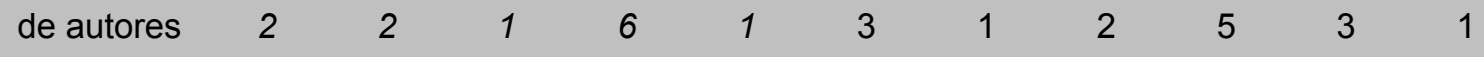

$\left(n^{\circ}\right)$

Fonte: Autores, com base na Brapci, (2019).

Esse periódico foi editado entre 1972 a 2014, com algumas interrupções e se constituiu um dos importantes periódicos científicos brasileiros na área de Arquivologia. Assim, é pertinente destacar que o periódico é Qualis B1 no quadriênio 2013-2016, porém foi descontinuado em 2015 com a extinção da entidade AAB. O periódico apresentou um ciclo de periodicidade e vivacidade no decorrer de sua trajetória, sendo disseminado em amplas bases informacionais.

\subsection{Archeion Online}

A 'Archeion Online' é em geral publicada nos meses de junho e dezembro e tem como editora e agência de fomento a Universidade Federal da Paraíba (UFPB) e, segundo Carvalho (2013), o periódico eletrônico surgiu em 2013 a partir da necessidade de divulgar a produção científica da Arquivologia e do respectivo bacharelado da UFPB.

O título da revista foi escolhido a partir de um concurso realizado pela Coordenação de Arquivologia da UFPB, tendo como ganhadores os estudantes François Braga de Azevedo Filho e João Paulo Silva de Souza (CARVALHO, 2013). Carvalho (2013, p. 1) esclarece que o título representa para os dois discentes o resgate do termo 'Archeion', utilizado como definições iniciais do que 'significa Arquivo', e o termo atual 'Online', consolidando-se assim que o Arquivo acompanhou todas as transformações da Sociedade diante das novas Tecnologias de Informação e Comunicação.

A revista "Archeion Online" é uma transposição da ideia de "Archeion" denominando o lugar onde se redige e conserva os documentos em junção como o prefixo "arch" significa comando ou autoridade e deriva de "Arkhaios" que designa 'o mais antigo' e assim, em latim há o registro "archivum" e no português o termo surge para designar 'arquivo' (CARVALHO, 2013).

A Archeion Online é uma revista eletrônica cientifica da Ciência da Informação e tem por objetivo estimular e publicar artigos produzidos pelos discentes, docentes 


\section{(2) Bibliocantos}

e pesquisadores em geral da área de Arquivologia e/ou áreas afins. O periódico tem periodicidade semestral publicando artigos originais e resultados da pesquisa de Teses, dissertações, iniciação científica, práticas da extensão universitária e outras investigações que enriqueçam a Ciência da Informação, difundindo o ensino, a pesquisa e a extensão (CARVALHO, 2013).

Dessa forma, a revista contribui com a arquivística no cenário acadêmico brasileiro, aumentando o nível de conhecimento nessa área. A revista apresenta qualificação $C$.

No que tange arquivos privados, recupera-se na Brapci 14 itens documentais - totais segue na tabela 5 .

Tabela 5 - Artigos no Periódicos Archeion Online relacionado ao tema arquivos privados

\begin{tabular}{l|c|c|c|c|c|c|c}
\hline Ano & 2013 & 2014 & 2015 & 2016 & 2017 & 2018 & 2019 \\
\hline Quantidad & 1 & 2 & 2 & 2 & 4 & 3 & - \\
e & $7,14 \%$ & $14,29 \%$ & $14,29 \%$ & $14,29 \%$ & $28,57 \%$ & $21,43 \%$ & - \\
de artigos & & & & & & & \\
$\begin{array}{l}\text { Quantidad } \\
\text { e }\end{array}$ & 2 & 5 & 5 & 5 & 7 & 6 & - \\
de autores & & & & & & & \\
\hline
\end{tabular}

Fonte: Autores, com base na Brapci, (jun. 2019).

Em suma o periódico contribui para o alinhamento entre teoria e prática profissional atendendo à natureza da Arquivologia bem como da interdisciplinaridade com áreas afins, a revista da UFPB visa contribuir com a guarda e disseminação dos artigos científicos produzidos e promove a visibilidade dessa temática.

\subsection{Acervo: Revista do Arquivo Nacional}

Os trabalhos acadêmicos em periódicos científicos contribuíram para a difusão do conhecimento e para a formação de novos profissionais, reporta a Revista Acervo, publicação do Arquivo Nacional. O periódico visa a divulgar pesquisas de ponta realizadas no Brasil e no exterior, discutindo as diversas perspectivas e abordagens empregadas na análise interdisciplinar, a partir de diferentes documentos (imagens, trajes, textos, filmes, depoimentos orais, entre 


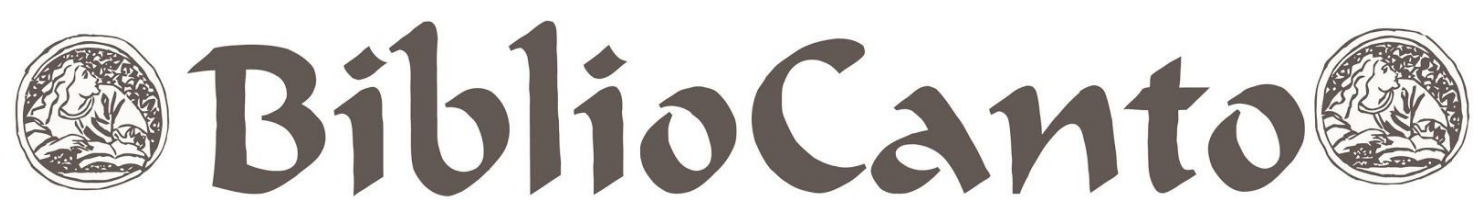

outros) numa ampla cronologia. Assim, publica-se somente trabalhos inéditos em português, espanhol e inglês, submetidos por meio do sistema Open Journal Systems (OJS).

Acervo, portanto, é a revista do Arquivo Nacional e foi criada em 1986; apresenta periodicidade quadrimestral e têm por objetivo divulgar estudos e fontes nas áreas de ciências humanas e sociais aplicadas, especialmente atinentes a arquivologia e história.

O periódico tem seções - que advém do processo de avaliação por pares - e voltada ao Dossiê Temático (número especial que apresenta um conjunto de artigos sobre o tema selecionado), Artigos Livres (resultantes de estudos e pesquisas), Documento (textos técnicos sobre o acervo do Arquivo Nacional) e seções direcionadas a Resenha (texto crítico sobre obra recente - livro ou filme) e Entrevista.

Esse periódico aceita artigos de natureza teórica e epistemológica, discussões e reflexões político-filosóficas entre outras opções para as seções Dossiê Temático, Artigos Livres, Resenhas e Documentos. Encontra-se sob o tema pesquisa 14 autores e um total de artigos 11, como mostra a tabela 6.

Tabela 6 - Artigos de Periódicos relacionado conforme busca na Brapci

\begin{tabular}{lllllllll|l}
\hline Ano & 2011 & 2013 & 2014 & 2016 & 2017 & 2018 & 2019 \\
\hline Quantidade de artigos & 2 & 2 & 2 & 2 & 1 & 1 & 1 \\
& $18,20 \%$ & 18,20 & 18,20 & 18,20 & & & 9,10 \\
& & $\%$ & $\%$ & $\%$ & $9,10 \%$ & $9,10 \%$ & $\%$ \\
$\begin{array}{l}\text { Quantidade de } \\
\text { autores }\end{array}$ & 2 & 4 & 2 & 2 & 1 & 1 & 2 \\
\hline
\end{tabular}

Fonte: Autores, com base na Brapci, (2019).

A revista teve em seu percurso de vida várias edições temáticas e especiais (número comemorativo); em 2018, por exemplo, ouve chamadas para publicação direcionada ao "Estado da arte da pesquisa em Arquivologia" - tal temática buscou pautar a realidade dos arquivos no presente e suas perspectivas de desenvolvimento no futuro, contemplando ainda os debates no âmbito dos documentos digitais. 


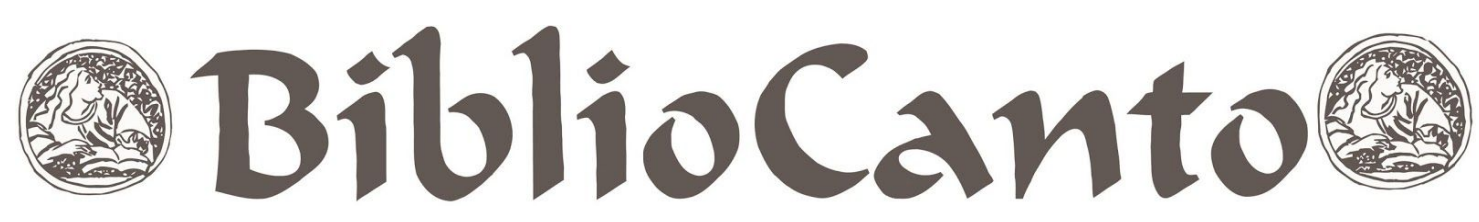

\subsection{Memórias, Praxia e Particularidades em Pauta}

Outras mudanças também acenam nesse palco, seja na capacidade de recuperar registros na base de dados, seja no potencial criativo, agregador e transformador que os arquivos privados apresentam. Assim, a figura 4 a seguir representa a forma de comunicações científicas envolvendo a temática arquivos privados, em termo de quantitativos de pesquisadores envolvidos.

Figura 4 - Expressão da autoria e coautoria na produção acadêmica de arquivos privados

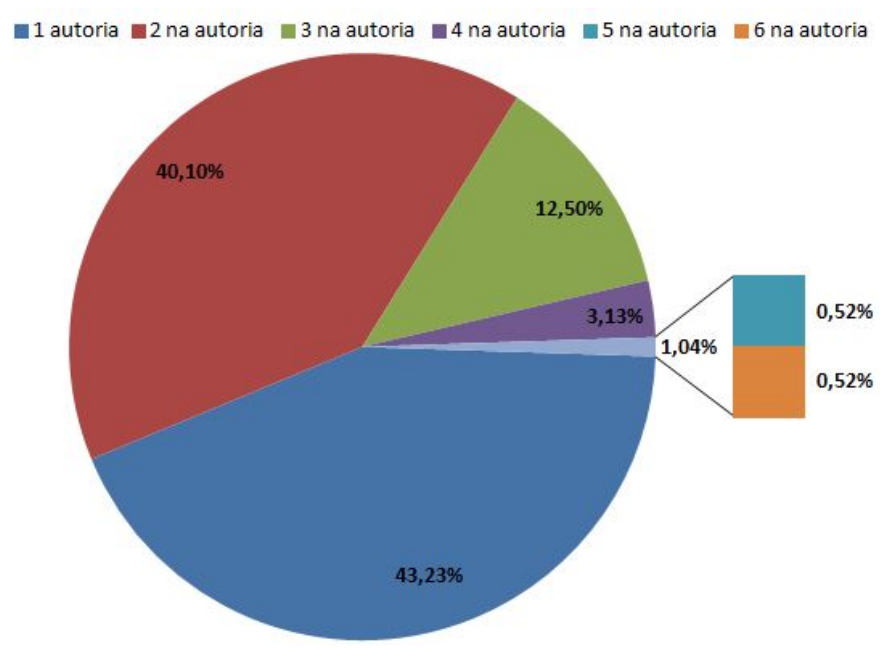

Fonte: Autores, com base nos dados 207 itens documentais da Brapci, (jun. 2019).

Observa-se assim, pela busca e organização dos artigos localizados na Brapci, uma mudança em prol da ciência aberta e na construção de redes de colaboração; esse dois elementos representam questões que pautam a qualidade e as interações (colégio invisível) rumo a investigações de maior impacto conceitual e prático na literatura científica mundial.

Nessa multiplicidade de documentos (207 itens documentais) há história, praxia e particularidades de muitos lugares de memória. Destaca-se ainda que há um "interesse crescente pelos arquivos privados corresponde a uma mudança de rumo fundamental na história das práticas historiográficas" (PROCHASSON, 1998, p. 109).

Cabe também destacar que no rol de dados temos os autores com mais publicações de 'arquivos privados' conforme resultados dos itens recuperados na 


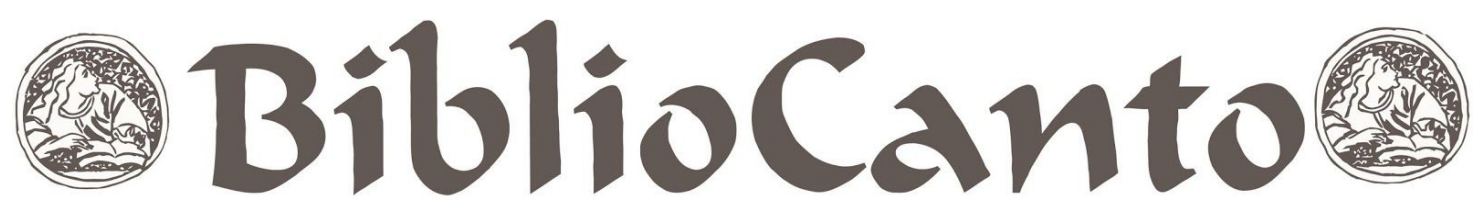

Brapci. Paralelamente, consultou-se a plataforma do Currículo Lattes para confrontar as informações referentes à titulação e à instituição de origem dos autores. $\mathrm{Na}$ tabela 7, apresentam-se os autores, titulação e suas respectivas instituições em associação com a temática - Arquivos Privados, Pessoais, Familiares, Empresarias e Familiares.

Tabela 7 - Perfil dos autores mais produtivos de acordo com sua titulação e instituição

\begin{tabular}{|c|c|c|c|c|}
\hline Autores & Instituição & Vínculo & Titulação & Artigos \\
\hline $\begin{array}{l}\text { OLIVEIRA, } \\
\text { Bernardina Maria } \\
\text { Juvenal Freire }\end{array}$ & $\begin{array}{l}\text { Universidade Federal } \\
\text { da Paraíba (UFPB) }\end{array}$ & Docente & $\begin{array}{l}\text { Doutora em } \\
\text { Letras }\end{array}$ & 6 \\
\hline $\begin{array}{l}\text { SILVA, Maria } \\
\text { Celina Soares }\end{array}$ & $\begin{array}{l}\text { Museu de Astronomia e } \\
\text { Ciências Afins (MAST) }\end{array}$ & Docente & $\begin{array}{l}\text { Doutora em } \\
\text { História Social }\end{array}$ & 5 \\
\hline $\begin{array}{l}\text { GHANEM, Valéria } \\
\text { Gouvêa }\end{array}$ & $\begin{array}{l}\text { Tribunal de Contas do } \\
\text { Estado de Santa } \\
\text { Catarina }\end{array}$ & $\begin{array}{l}\text { Servidora do } \\
\text { TCE/SC }\end{array}$ & $\begin{array}{l}\text { Especialista em } \\
\text { Organização de } \\
\text { Arquivos }\end{array}$ & 4 \\
\hline $\begin{array}{l}\text { RODRIGUES, } \\
\text { Georgete Medleg }\end{array}$ & $\begin{array}{l}\text { Universidade de } \\
\text { Brasília (UnB) }\end{array}$ & Docente & $\begin{array}{l}\text { Doutora em } \\
\text { História }\end{array}$ & 4 \\
\hline $\begin{array}{l}\text { ALBUQUERQUE, } \\
\text { Ana Cristina }\end{array}$ & $\begin{array}{l}\text { Universidade Estadual } \\
\text { de Londrina (UEL) }\end{array}$ & Docente na & $\begin{array}{l}\text { Doutora em } \\
\text { Ciência da } \\
\text { Informação }\end{array}$ & 3 \\
\hline $\begin{array}{l}\text { BAHIA, Eliana } \\
\text { Maria dos Santos }\end{array}$ & $\begin{array}{l}\text { Universidade Federal } \\
\text { de Santa Catarina } \\
\text { (UFSC) }\end{array}$ & Docente & $\begin{array}{l}\text { Doutora Em } \\
\text { Ciência Da } \\
\text { Informação }\end{array}$ & 3 \\
\hline $\begin{array}{l}\text { BARROS, Thiago } \\
\text { Henrique Bragato }\end{array}$ & $\begin{array}{l}\text { Universidade Federal } \\
\text { do Rio Grande do Sul } \\
\text { (UFRGS) }\end{array}$ & Docente & $\begin{array}{l}\text { Doutor em } \\
\text { Ciência da } \\
\text { Informação }\end{array}$ & 3 \\
\hline $\begin{array}{l}\text { BRITTO, Augusto } \\
\text { César Luiz }\end{array}$ & $\begin{array}{l}\text { Universidade Federal } \\
\text { de Santa Maria (UFSM) }\end{array}$ & Docente & $\begin{array}{l}\text { Mestre em } \\
\text { Comunicação, } \\
\text { Linguagens e } \\
\text { Cultura }\end{array}$ & 3 \\
\hline $\begin{array}{l}\text { CAVAGLIERI, } \\
\text { Marcelo }\end{array}$ & $\begin{array}{l}\text { Serviço Nacional de } \\
\text { Aprendizagem } \\
\text { Comercial (Senac) }\end{array}$ & Bibliotecário & $\begin{array}{l}\text { Mestre em } \\
\text { Gestão da } \\
\text { Informação }\end{array}$ & 3 \\
\hline
\end{tabular}




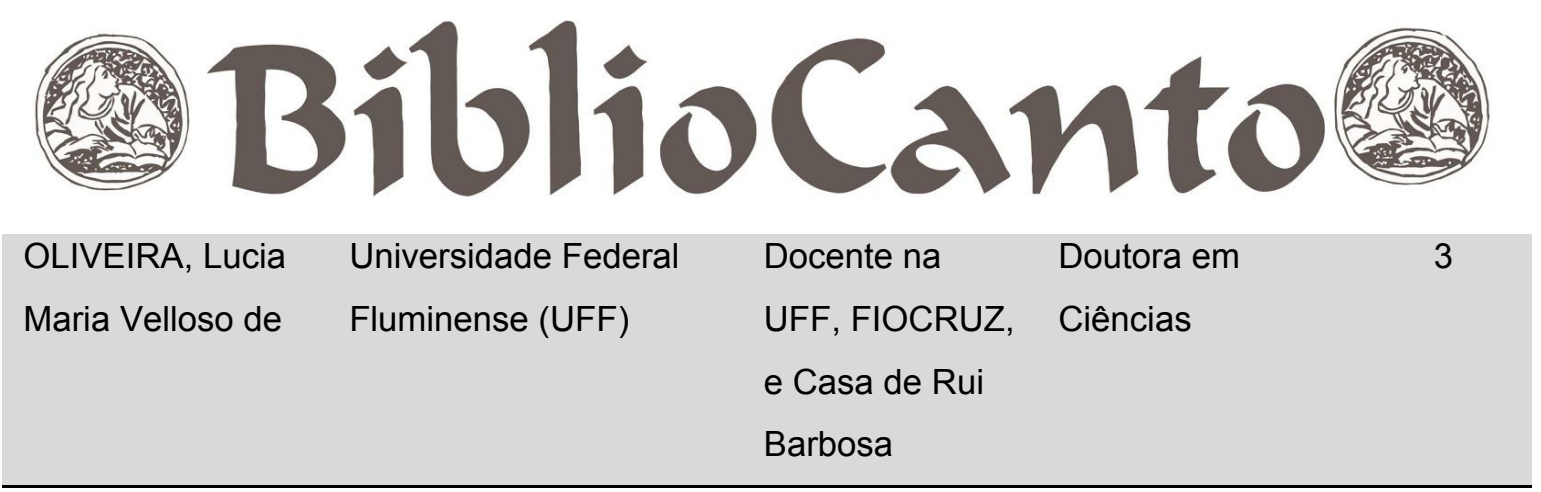

Fonte: Autores, com base em brapci.inf.br e buscatextual.cnpq.br | 298 autores (1975-2019).

Observa-se ainda que a temática 'Arquivos Privados' é pouco explorada na pós-graduação brasileira na área de $\mathrm{Cl}$ e a Brapci recupera apenas 16 estudos com tal temática no ENANCIB de 2018. Estranha-se ainda que existam três grupos de pesquisa no Conselho Nacional de Pesquisas (CNPq) o que referencia um potencial para crescimento nas esferas do fazer - saber científico nacional.

Destarte, a Base de Dados Referencial de Artigos de Periódicos em Ciência da Informação (Brapci) facilita a obtenção dos dados e possibilita a realização de novos olhares sobre as temáticas da área de arquivologia e da $\mathrm{Cl}$.

\section{CONSIDERAÇÕES FINAIS}

Esta pesquisa bibliográfica analisou quais são as revistas na área da Arquivologia e Ciência da Informação que publicam o tema 'arquivos privados' e pertinentes correlações em título, palavras-chave, resumo e referências dos artigos. Assim, pesquisadores relevantes como Araújo e Alvarenga (2011) apontam que análise bibliométrica tem um papel relevante para se descobrir a produção científica país e das instituições.

Dessa forma, recorrendo-se a Brapci - um Acervo de Publicações Brasileiras em Ciência da Informação - foram recuperados e identificados 261 artigos publicados (de 1975 a jun. de 2019), em 39 revistas distintas edições do ENANCIB, dando enfoque especial a questão de Arquivos Privados.

Verificou-se que os periódicos com maior representatividade (canais de informação científica desse tema) na área de arquivos privados/pessoais são: a Revista Ágora (Florianópolis); Revista Arquivo \& Administração (descontinuada) da Associação dos Arquivistas Brasileiros; a Revista Archeion Online do Departamento de Ciência da Informação da UFPB e; a Revista Acervo, periódico quadrimestral do 


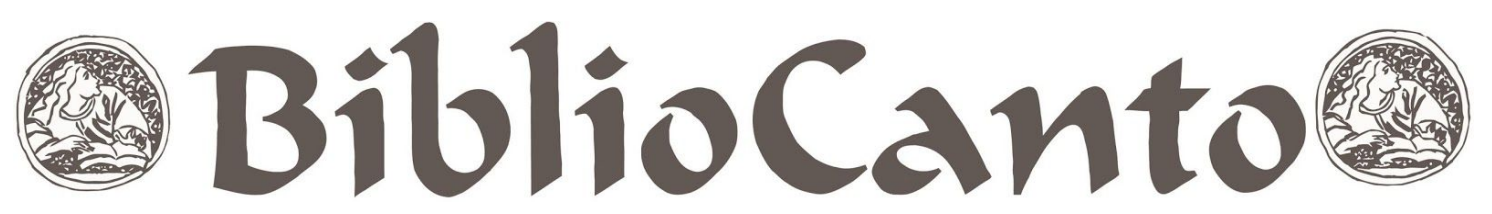

Arquivo Nacional

Os autores mais produtivos na área de arquivo privado segundo busca na Bracip são: Bernardina Maria Juvenal Freire Oliveira, da Universidade Federal da Paraíba - UFPB, com seis artigos publicados; Maria Celina Soares Silva, pesquisadora do Museu de Astronomia e Ciências Afins - MAST, com cinco artigos publicados; e com respectivamente quatro publicações destacam-se as doutoras Georgete Medleg Rodrigues (da Universidade de Brasília - Unb) e Valéria Gouvêa Ghanem (do Tribunal de Contas do Estado de Santa Catarina - TCE/SC).

Embora não seja um estudo exaustivo, pois sabe-se que vários periódicos brasileiros ainda não aparecem na base, pode dar uma dimensão do resultado, uma vez que a Brapci tem cobertura temática e temporal. Por outro lado, a base tem ampliado, significativamente, o número de periódicos e, consequentemente, o número de artigos indexados. Por outro lado, a Brapci aumenta sua abrangência e tem ampliado, significativamente, o número de periódicos e, consequentemente, o número de artigos indexados.

Por fim, recomenda-se que sejam realizados estudos para averiguar como a temática adentra no currículo dos bacharéis em arquivologia pelo país para identificar quais Instituições de Ensino Superior ofertam as disciplinas, e quais diretrizes abrangem. Portanto esse tema merece ser estudado em suas diferentes dimensões, pois reflete claramente no campo de atuação profissional da arquivística e da informação e comunicação. Desta forma, considera-se que indicadores bibliométricos contribuem amplamente para entender e pautar novos estudos acerca dos 'arquivos privados' na ciência, tecnologia e recriação (entre mídia, produção cinematográfica e artística enfocando tal contexto ou entendimento fenômeno cultural resultante).

Abstract: The study comprises a bibliographic research that analyzes the theme "Private Archives" in the journals of Information Science. To identify the material was used the Reference Database of Journals on Information Science (BRAPCI). The analysis focuses on three ambits: a) To raise the articles published on Private 


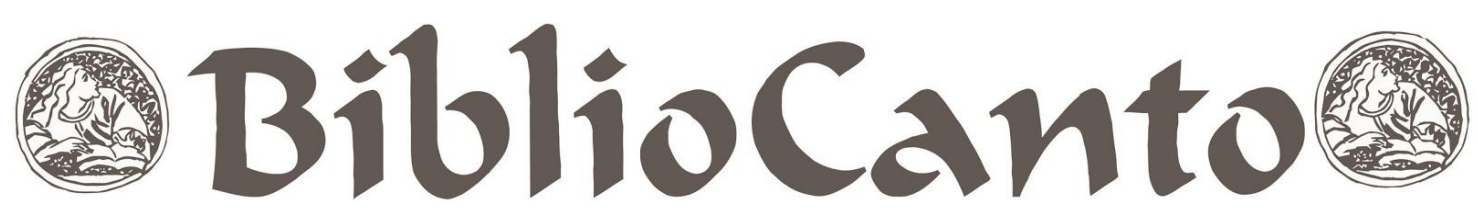

Archives in Information Science journals; b) Check which journals are most representative for the archival area; c) Describe the profile of the most productive authors of Private Archives according to their title and institution of origin. As a result, 317 articles were observed, of which 207 fit the parameters established for this study. Thus the research revealed three active journals that most published the theme 'Personal Archives' are: Agora: Archivology In Debate, with 41 articles; Archeion Online with 14 articles; Collection: National Archive Magazine with 11 articles; and the discontinued magazine Archive \& Administration with 21 articles.

Keywords: Private Archives. Thematic analysis. Bibliometrics. Scientific production. Scientific Journals.

\section{REFERÊNCIAS}

ACERVO: REVISTA DO ARQUIVO NACIONAL. Rio de Janeiro, Arquivo Nacional: Ministério Da Justiça E Segurança Pública, 1985-. Disponível em: http://www.brapci.inf.br/index.php/res/v/780. Acesso em: 29 jul. 2019.

ÁGORA: ARQUIVOLOGIA EM DEBATE. Florianópolis: Universidade Federal de Santa Catarina, 1985-. Disponível em:

https://agora.emnuvens.com.br/ra/issue/archive. Acesso em: 27 jul. 2019.

ARAÚJO, R. F.; ALVARENGA, L. A bibliometria na pesquisa científica da pós-graduação brasileira de 1987 a 2007 . Encontros Bibli: revista eletrônica de biblioteconomia e ciência da informação, Florianópolis, v. 16, n. 31, p. 51-70, mar. 2011. Disponível em: https://doi.org/10.5007/1518-2924.2011v16n31p5 . Acesso em: 30 jul. 2019.

ARCHEION ONLINE. João Pessoa, Universidade Federal da Paraíba, 2013-. Disponível em: http://www.brapci.inf.br/index.php/res/v/96. Acesso em: 30 jul. 2019.

ARQUIVO E ADMINISTRAÇÃO. Rio de Janeiro: Associação dos Arquivistas Brasileiros: Biblioteca Maria Beatriz Nascimento, 1972- 2014. Disponível em: http://www.brapci.inf.br/index.php/res/v/694. Acesso em: 28 jul. 2019.

BUFREM, L. S. et al. Modelizando práticas para a socialização de informações: a construção de saberes no ensino superior. Perspectivas em Ciência da Informação, v. 15, n. 2, p. 22-41, ago. 2010.

CALDERON, W. R. O arquivo e a informação arquivística: da literatura científica à prática pedagógica no Brasil. São Paulo: Cultura Acadêmica, 2013. 


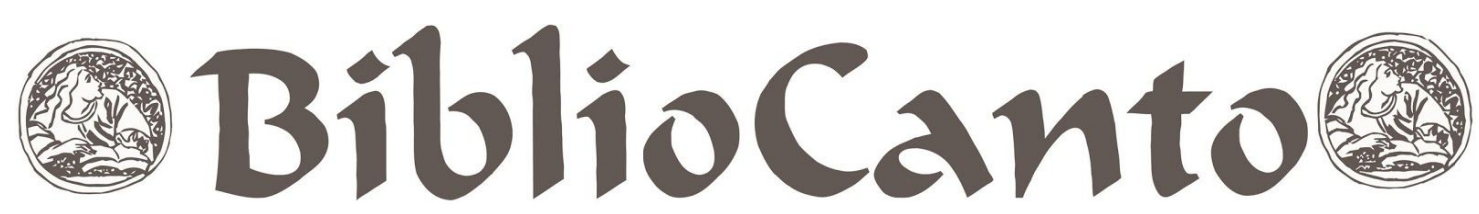

CAMARGO, A. M. A. Arquivos pessoais são arquivos. Revista do Arquivo Público Mineiro, Belo Horizonte, v. 45, n. 2, p. 27-39, 2009.

CARVALHO, E. T. G. Editorial: Archeion Online periódico eletrônico de Arquivologia. Archeion Online, v.1, n.1, p. 7-8, jul./dez. 2013.

CHAVES, M. A. Arquivos empresariais como fonte para a produção da História.

Revista de fontes, v. 4, n. 7, p. 15-24, 2017.

DIBRATE: ARQUIVO NACIONAL (Brasil). Dicionário Brasileiro De Terminologia Arquivística - Dibrate. Rio de Janeiro: Arquivo Nacional, 2005.

FRAIZ, P. A dimensão autobiográfica dos arquivos pessoais: o arquivo de Gustavo Capanema. Revista Estudos Históricos, Rio de Janeiro, v. 11, n. 21, p. 59-88, jul. 1998. Disponível em:

http://bibliotecadigital.fgv.br/ojs/index.php/reh/article/view/2060\%3B . Acesso em: 26 jul. 2019.

FUNDAÇÃO GETULIO VARGAS. Accessus - Documentos de Arquivos

Pessoais: o que são Arquivos Pessoais. 2017. Disponível em:

https://cpdoc.fgv.br/acervo/arquivospessoais . Acesso em: 22 Jul. 2019.

LOPEZ, André Porto Ancona. Arquivos Pessoais e as Fronteiras da Arquivologia.

Gragoatá, Niterói, n. 154, p. 69-82, 2003.

MOLINA, T. S. Arquivos privados e interesse público: caminhos da patrimonialização documental. Acervo, Rio de Janeiro, v. 26, n. 2, p.160-174, jul./dez. 2013.

MOURA, M. M. A. de; GARCIA, M. Os documentos pessoais no espaço público.

Revista Estudos Históricos, v. 11, n. 21, p. 175-187, 1998. Disponível em: http://bibliotecadigital.fgv.br/ojs/index.php/reh/article/view/2070/1209. Acesso em 22 mar. 2019.

OLIVEIRA, L. M. V. Descrição e Pesquisa: Reflexões em torno dos Arquivos Pessoais. Rio de Janeiro: Móbile, 2012.

PIAZZA, W. F. Apresentação. ÁGORA: Arquivologia em debate, Florianópolis, v. 1, n. 1, p. 3, set. 1985. Disponível em:

https://agora.emnuvens.com.br/ra/article/view/36. Acesso em: 07 jul. 2019.

PROCHASSON, C. Atenção: verdade! Arquivos privados e renovação das práticas historiográficas. Revista Estudos Históricos, Rio de Janeiro, v. 11, n. 21, p. 105-120, jul. 1998. Disponível em: http://bibliotecadigital.fgv.br/ojs/index.php/reh/article/view/2064. Acesso em: 29 jul. 2019. 


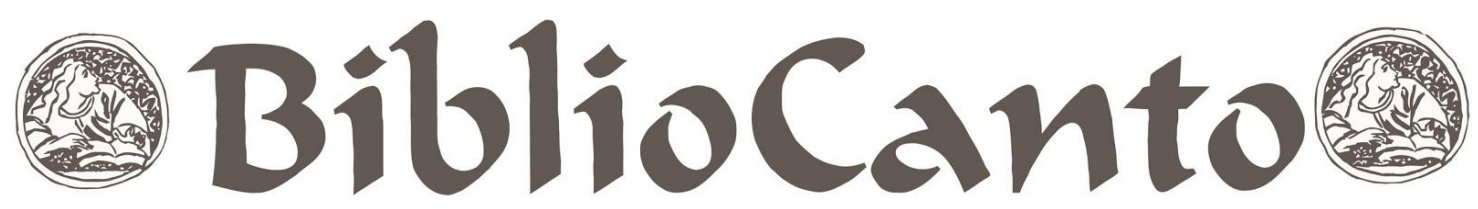

SILVA, M.; HAYASHI, C. R.; HAYASHI, M. C. Análise bibliométrica e cientométrica: desafios para especialistas que atuam no campo. InCID: Revista de Ciência da Informação e Documentação, v. 2, n. 1, p. 110-129, 9 jun. 2011.

VANZ, S.; SANTIN, D.; PAVÃO, C. A bibliometria e as novas atribuições profissionais nas bibliotecas universitárias. InCID: Revista de Ciência da Informação e Documentação, v. 9, n. 1, p. 4-24, jun. 2018.

VIANNA, Aurélio; LISSOVSKY; Maurício, SÁ; Paulo Sérgio Moraes. A vontade de guardar: lógica da acumulação em arquivos privados. Arquivo \& Administração, v. 2, n. 10, p. 62-76, 1986. Disponível em:

http://www.brapci.inf.br/index.php/article/view/0000003806. Acesso em: 11 nov. 2019.

VITORIANO, M. C. C. P. A presença de fundos privados institucionais nos arquivos públicos estaduais do Brasil. In: GUELFI, J. F. (org.). Arquivos privados: abordagens plurais. São Paulo: ARQ-SP, 2016. 